\title{
Rare Case of Vaginal Delivery in Giant Aortic Aneurysm
}

\author{
Ekaterina Luneva, MD, $\mathrm{PhD}^{1 *}$, Maria Samokhvalova, $\mathrm{MD}, \mathrm{PhD}^{2}$, Artem Pakhomov, $\mathrm{MD}, \mathrm{PhD}^{3}$, \\ Lubov Mitrofanova, MD, DSc ${ }^{4}$, Eduard Malev, MD, PhD ${ }^{1}$, Vladimir Uspenskiy MD, PhD $^{5}$ \\ ${ }^{1}$ Department of Connective Tissue Disorders, North-West Federal Medical Research Center, St Petersburg, Russia \\ 2 Department of Radiology, Clinic Skandinavia, St Petersburg, Russia \\ ${ }^{3}$ Medical Director, PLC CMRI, St Petersburg, Russia \\ ${ }^{4}$ Department of Pathomorphology, North-West Federal Medical Research Center, St Petersburg, Russia \\ ${ }^{5}$ Department of Cardiothoracic Surgery, North-West Federal Medical Research Center, St Petersburg, Russia
}

\begin{abstract}
A 33-year-old woman underwent successful vaginal delivery despite previously unsuspected $8-\mathrm{cm}$ ascending and $6-\mathrm{cm}$ descending aortic aneurysms. These were repaired immediately after delivery.

Copyright (c) 2015 Science International Corp.
\end{abstract}

\section{Key Words}

Aortic aneurysm • Vaginal delivery • Aortic dissection

It is well known that aortic dissection is a serious problem during pregnancy due to increased risk of maternal death [1]. In some congenital and genetic disorders (Marfan syndrome, bicuspid aortic valve, aortic coarctation), the natural history of the disease is well-known. However, there are a number of congenital heart diseases with aortic dilatation that are not well characterized. We present here a rare case of successful vaginal delivery in a patient with large ascending and descending aortic aneurysms, previously unsuspected.

A 33-year-old woman was admitted to the hospital 20 days after her first vaginal delivery from an outside hospital. She complained of chest pain during and after delivery. The patient had no family history of aortic disease or known connective tissue disorders.

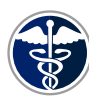

Fax +1 2037853552

E-Mail: aorta@scienceinternational.org

http://aorta.scienceinternational.org

\author{
(c) 2015 AORTA \\ Published by Science International Corp. \\ ISSN 2325-4637 \\ Accessible online at: \\ http://aorta.scienceinternational.org
}

On examination, there were no signs of genetic disorders such as Marfan syndrome, or Ehlers-Danlos syndrome. On echocardiography an aneurysm of the ascending aorta was found, with severe aortic regurgitation. The aortic valve was tricuspid. On computed tomography (CT) scan, the aneurysms of ascending and descending aorta were identified, with maximum size of the ascending aorta of $81 \mathrm{~mm}$ and maximum size of the descending aorta of $61 \mathrm{~mm}$. There were no signs of aortic dissection (Figure 1).

The patient underwent a Bentall-De Bono procedure with the Kouchoukos modification with hemiarch reconstruction. Histology of aorta showed cystic medial degeneration with pseudocyst formation in the media, accompanied by extensive loss of elastic lamina. On control CT before the second stage of operation which was performed in 6 months time, enlargement of descending aorta and aortic dissection were found (Figure 2). The dissection of the descending aorta developed after Stage 1 of the operation and there were no signs of dissection on initial scans. The size of the aorta enlarged dramatically from $61 \mathrm{~mm}$ to $67 \mathrm{~mm}$. Endovascular treatment of the descending aorta with Valliant Thoracic Captiva stent graft was performed. The stent graft did not cover

\footnotetext{
* Corresponding Author:

Ekaterina Luneva, MD, PhD

Department of Connective Tissue Disorders

North-West Federal Medical Research Center

Akkuratova st, 2, St Petersburg, 197341, Russia

Tel. +7 812 7023749, Fax: +7 821 7023744, E-Mail: e.luneva@hotmail.com
} 


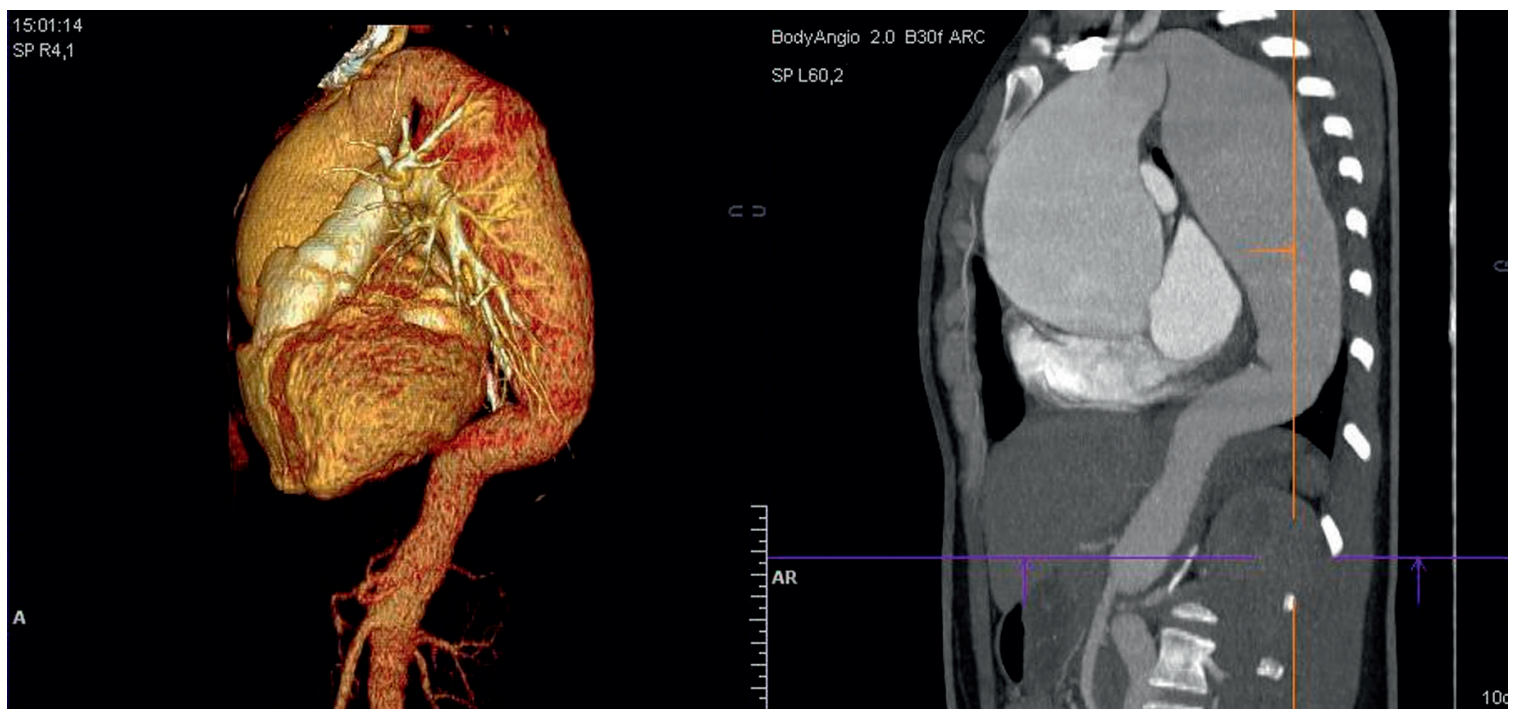

Figure 1. CT-aortography after vaginal delivery. There are signs of dilatation of ascending and descending thoracic aorta without aortic dissection.

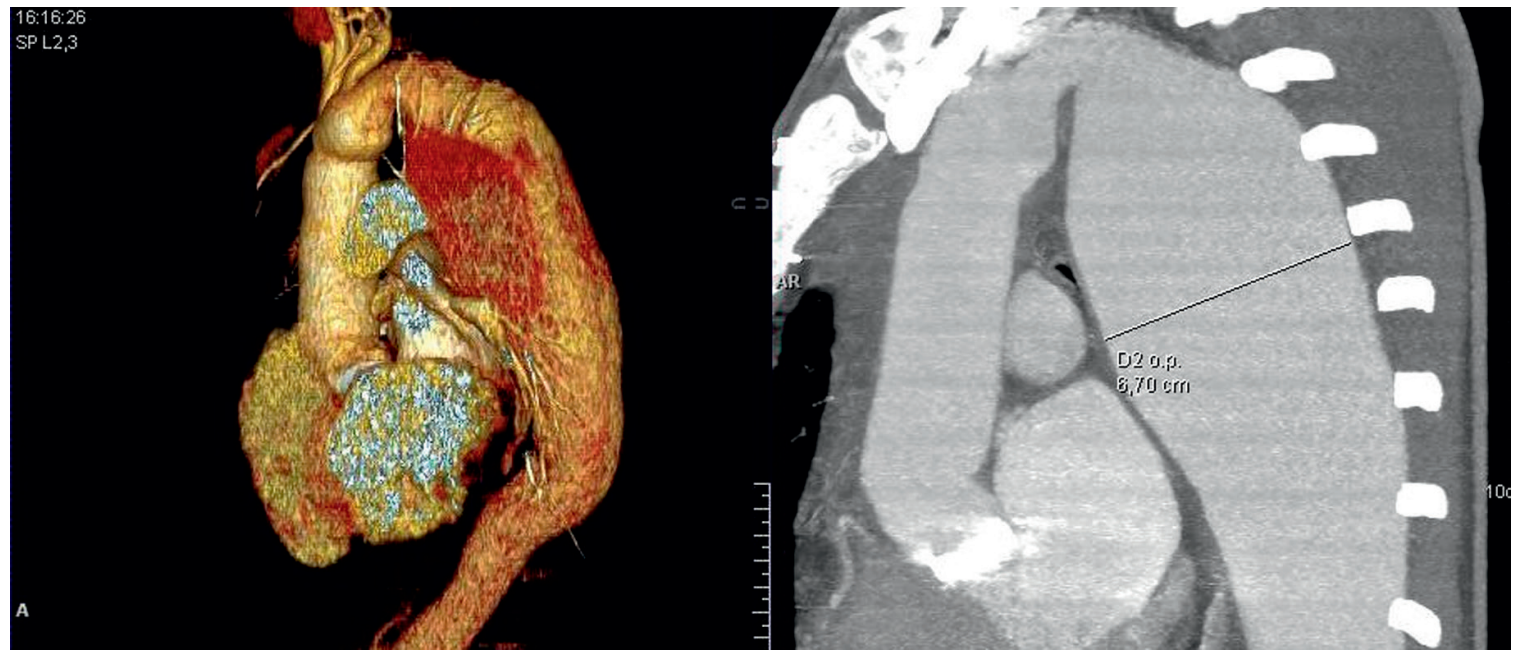

Figure 2. On CT-aortography after Stage 1, a conduit of the ascending aorta is shown. The descending aorta is enlarged and visibly larger than on Figure 1.

any of the great vessels. On control CT performed 6 months after the procedure there were no signs of deterioration (Figure 3).

This is a unique case of vaginal delivery in a woman with giant aortic aneurysm that was not complicated by dissection during delivery. It is well known that aortic aneurysms in young patients are usually associated with connective tissue disorders such as Marfan syndrome, or bicuspid aortic valve. We presume that aortic dissection in this patient was part of the natural history of nonsyndromic familial thoracic aortic aneurysm. In the 2014 European Society of Cardiology Guidelines on the diagnosis and treatment of aortic diseases, a new section on non-syndromic familial thoracic aortic aneurysm and dissection was included [2]. Numerous etiologic mutations have been identified. Routine echocardiography is not recommended 


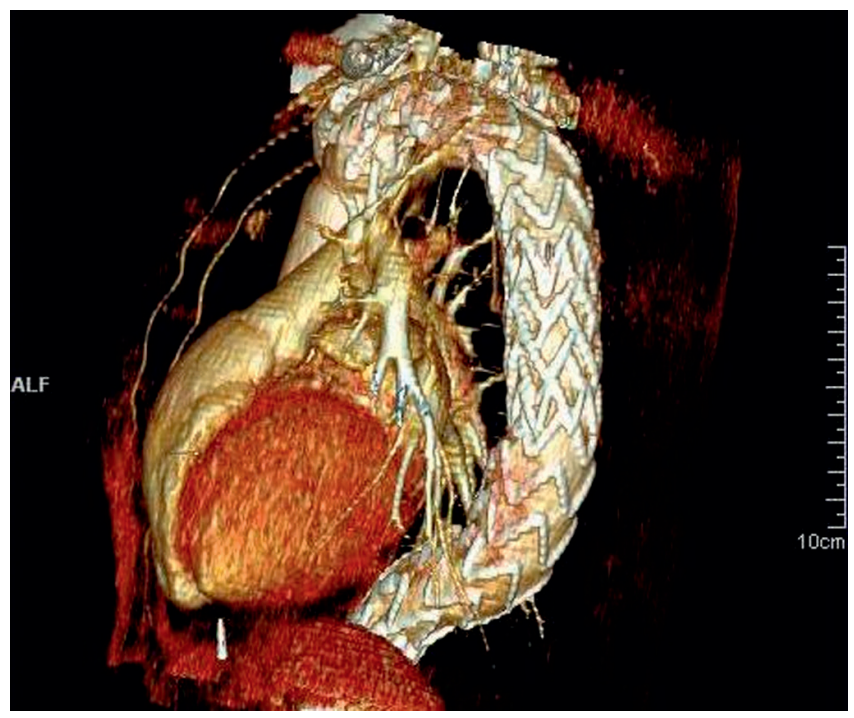

Figure 3. After Stage 2, a CT image shows a well-positioned stent-graft in the descending aorta. for all pregnant women without previous cardiac medical history. That is most likely the reason why in this patient the aortic enlargement was undetected due to lack of family history of aortic disease.

\section{Conflict of Interest}

The authors have no conflict of interest relevant to this publication.

\section{Comment on this Article or Ask a Question}

\section{References}

1. Immer FF, Bansi AG, Immer-Bansi AS, McDougall J, Zehr KJ, Schaff HV. Aortic dissection in pregnancy: Analysis of risk factors and outcome. Ann Thorac Surg. 2003;76:309-314. DOI: 10.1016/S0003-4975 (03)00169-3

2. Erbel R, Aboyans V, Boileau C, Bossone $\mathrm{E}$, Bartolomeo RD, Eggebrecht $\mathrm{H}$, et al. 2014 ESC Guidelines on the diagnosis and treatment of aortic diseases: Document covering acute and chronic aortic diseases of the thoracic and abdominal aorta of the adult. The Task Force for the Diagnosis and Treatment of Aortic Diseases of the European Society of Cardiology (ESC). Eur Heart J. 2014;35:2873-2926. DOI: 10.1093/ eurheartj/ehu281
Cite this article as: Luneva $E_{\text {, }}$ Samokhvalova $M$, Pakhomov A, Mitrofanova L, Malev E, Uspenskiy V. Rare Case of Vaginal Delivery in Giant Aortic Aneurysm. AORTA (Stamford). 2015;3(3):118-120. DOI: http://dx.doi. org/10.12945/j.aorta.2015.14.070 